\title{
Prospective of Energy Efficiency Practice, Indicator and Power
}

\section{Supplies Efficiency}

\author{
Anwar Al-Mofleh \\ Department of Electrical and Electronic Engineering, University Science of Malaysia \\ Nibong Tebal, Penang, Malaysia \\ Soib Taib \\ Department of Electrical and Electronic Engineering, University Science of Malaysia \\ Nibong Tebal, Penang, Malaysia \\ E-mail: soibtaib@eng.usm.my \\ Wael Salah \& Mokhzaini Azizan \\ Department of Electrical and Electronic Engineering, University Science of Malaysia \\ Nibong Tebal, Penang, Malaysia
}

\begin{abstract}
Energy efficiency generates substantial financial savings while at the same time improving environmental, business, home, and transport benefit. The efficiency of energy use will lead to a reduction in national energy consumption, as well as by improving energy efficiency the cost of using energy can be kept low and not blown out of proportion. The concept of energy efficiency will be in the interest of both customers and manufacturers because of its financial advantages. Energy-efficiency standards and labels can be the most effective long-term energy-efficiency policy any government can implement. Improving energy efficiency of power supply is one of the most cost-effective and feasible option to meet the energy efficiency practices.
\end{abstract}

Keywords: Energy Efficiency, Indicators, Standard and label, Power supply

\section{Introduction}

Energy is necessary as resources of production and for its contribution to the quality of life. As a result, economic growth is strongly connected to energy consumption. As the development continues, the increasing demand for energy is followed by environmental problems and finally, the limits of energy resources. Energy efficiency is recognized as a key to soften the strained link between economic growth and the increase in energy consumption. Energy efficiency offers both financial and environmental benefits as well as benefits in energy security. Since the oil crises in the 1970's, a considerable increase in energy efficiency has been achieved in response to energy price increases and supply uncertainties, government policies, and independent technology improvements (IEA, 1997b). Saving energy brings benefits in term of technical and financial point of view and helps, indirectly, to combat climate change all around the world. It concerns all aspects of life and all application, and the building of an energy efficient system will help the change towards renewable energy supplies (Salmon 1996, Seabright 1996). Energy efficiency is a generic term which refers to using less energy to produce the same amount of services or useful output (Patterson, 1996). As mentioned by Bosseboeuf et al. (1997) two types of energy efficiency aspects are defined as; a) Economic energy efficiency means more production or better standard of living with the same or reduced amount of energy, and b) Techno-economic energy efficiency relates to a reduction in specific energy due to technical improvement, changes in behavior, better management, etc. Figure 1 shows the levels of energy with their respective sources as well as the involved energy transformation processes.

By definition, there is no one unequivocal quantitative measure of energy efficiency. The selected energy input and useful output vary according to the nature of the analysis to be undertaken, ranging from the monitoring of energy efficiency in individual processes through to policy analysis and evaluation and the appraisal of new technologies. In general, the energy efficiency indicators are of the form (Patterson, 1996):

$$
\frac{\text { Useful output of a process }}{\text { Energy input of a process }}
$$


Competitive markets have been promoted to open by many countries, thereby stimulating economic growth. They have reduced or removed subsidies on energy prices. And energy conservation programs have motivated the wider adoption of energy efficiency technologies (Seabright 1996). The inverse of energy efficiency is often referred as energy intensity. The useful output of the process can be an energy output, a physically defined output, or it could be enumerated in monetary units. The task of energy efficiency indicators is basically the evaluation of the results achieved, evaluation of targets, and evaluation of the relative situations among peer groups. The indicators help the evaluation of different energy policies, programs, and energy conservation investments, give information on the current situation is today compared to trends in the past and in the future, as well as promote the spread of more efficient technologies and operation procedures. By constructing energy efficiency indicators that compare similar energy consuming processes and eliminate external influences, comparative static analysis can also be applied to identify a relative improvement potential (APERC, 2000).

\section{Factors Affecting Energy Efficiency:}

There are three factors that will determine the amount of energy efficiency objects its life as shown in Figure2:

- $\quad$ Design construction:

Issues such as the layout of the building, it is insulation standards, the efficiency of its services plant and the extent of automatic controls.

$\bullet$ Operation and maintenance:

Issues such as structural repairs, replacement cycles for consumable component, boiler servicing and the regular calibration/ adjustment of control system.

- $\quad$ Occupant activity:

Issues such as how much equipment its installed and how it is used staff working practices can also influence the amount of energy used for lighting and other building services.

These factors will operate independently decisions taken at the design stage can also facilitate effective operation and maintenance and reduce the impact of occupant activity (Kilponen, 2003, Phylipsen, et.al, 1998).

\section{Energy-Efficiency Labels And Standards}

Before discussing the many aspects of energy efficiency labels and standards that follow, we define exactly what is meant by these two terms.

\section{Labels:}

Energy-efficiency labels are informative labels that are affixed to manufactured products and describe a product's energy performance (usually in the form of energy use, efficiency, or energy cost) to provide consumers with the data necessary for making informed purchases. The labels then are differentiate with three of its kind (Duffy, 1996, CLASP, 2002):

$$
\begin{aligned}
& \text { - } \quad \text { Endorsement labels, } \\
& \text { - } \quad \text { Information-only labels. }
\end{aligned}
$$

Endorsement labels are essentially "seals of approval" given according to products that meet specified criteria. Comparative labels allow consumers to compare performance among similar products using either discrete categories of performance or continuous scale. Information-only labels simply provide data on a product's performance. Energy labels can stand alone or complement energy standards. They provide information that allows consumers who care to select efficient models. Labels also provide a common energy-efficiency benchmark that makes it easier for utility companies and government energy-conservation agencies to offer consumers incentives to buy energy-efficient products. The effectiveness of energy labels is highly dependent on how they present information to the consumer. The format of the label, the level of market support, and the credibility of the labeling program sponsor are all key factors.

\section{Standards}

Energy-efficiency standards are procedures and regulations that prescribe the energy performance of manufactured products, sometimes prohibiting the sale of products that are less energy efficient than the minimum standard (Meyers, et, al. 2003). The term standards commonly encompass two possible meanings:

1) Well-defined protocols (or laboratory test procedures) by which to obtain a sufficiently accurate estimate of the energy performance of a product in the way it is typically used, or at least a relative ranking of its energy performance compared to other models. 
2) Target limits on energy performance (usually maximum energy use or minimum efficiency) based upon a specified test protocol. (McMahon and Turiel, 1997). The term norm is sometimes used instead of standard in Europe and Latin America to refer to the target limit. There are three types of energy-efficiency standards:

- $\quad$ Prescriptive standards - requiring that a particular feature or device be installed (e.g., insulation) or not installed (e.g., pilot lights) in all new products;

- $\quad$ Minimum energy-performance standards (MEPS) - prescribing minimum efficiencies (or maximum energy consumption - usually as a function of size or capacity) that manufacturers must achieve in each and every product, specifying the energy performance but not the technology or design details of the product;

- Class-average standards - specifying the average efficiency of a manufactured product, allowing each manufacturer to select the level of efficiency for each model so that the overall average is achieved.

\section{Power Supply And Energy Efficiency}

Power supplies are responsible for large energy consumption due to the large number of external power supplies in use and to the low efficiency of many power supply types present on the market at different loads including losses at no-load condition. European Commission commissioned a study to investigate a number of devices with no-load and standby losses. The Study on Miscellaneous Standby Power Consumption of Household Equipment indicated that power supplies contribute substantially to the electricity consumption of households in Europe. The study calculated an increase in electricity consumption of external power supplies no-load losses (Bertoldim 2004).

In most cases these power supplies are specified by the appliance manufacturer; production can be at the appliance manufacturer or at a dedicated manufacturer. Many of the external power supplies coming to the European market have a very low efficiency across the load curve. The study not only addresses the size of the power supplies consumption while in stand-by or no load, but also the necessary policies to reduce this consumption. It was clear that the final users have little information and choice in the selection of external power supplies, as these were supplied with the equipment (e.g. mobile telephone, portable audio equipment, portable power tools, etc.). Improving the efficiency with which energy is consumed by end-users is a central theme of energy policy within the European Community. Moreover there is a close link between the development of renewable energy sources and the efficiency use of energy and electricity to maximize the benefit of renewable energy sources (http://energyefficiency.jrc.cec.eu.int/).

\section{Conclusion}

Energy efficiency now is a central focus of many national energy policies and at the front of the debate on energy sustainability issues. The development of more disaggregated structural indicators is the key to obtaining a better understanding of the evaluation of energy services demand. Moreover better measurement of the impact of life-styles is necessary for cross-country comparisons. Many techniques have been developed to minimize the dynamic and static power consumed. To achieve further savings it is necessary to employ methods that do constrain functionality to Improving energy efficiency of end-use equipment is one of the most cost-effective and feasible option to meet the energy and environmental policy objectives.

\section{References}

APERC (2000). Energy efficiency indicators, a study of energy efficiency indicators for industry in APEC economies. Asia Pacific Energy Research Centre. Tokyo. ISBN 4-931482-05-8. 154 pp.

Bosseboeuf, D., Chateau, B., Lapillonne, B. (1997). Cross-country comparison on energy efficiency indicators: The on-going European effort towards common methodology. Energy Policy 7-9(25), 673-682.

IEA. (1997a). Indicators of energy use and efficiency. Understanding the link between energy and human activity. International Energy Agency. 330 pp. ISBN 92-64-14919-8.

IEA. (1997b) Energy efficiency initiative, Vol. 1, Energy policy analysis, International Energy Agency, 193 pp.

Patterson, M.G. (1996). What is energy efficiency? Concepts, indicators and Methodological issues. Energy Policy 5(24), 377-390.

Phylipsen, G., Blok, K., and Worrell, E. (1998). Handbook on International Comparisons of Energy Efficiency in the Manufacturing Industry. Department of Science, Technology and Society, Utrecht University.

Kilponen, L. (2003). Energy efficiency indicators in integrated pulp and paper mill research scheme. Helsinki University of Technology, Laboratory of Energy Economics and Power Plant Engineering.

Meyers, S., McMahon, J.E., McNeil, M., Liu, X. (2004). Realized and Prospective Impacts of U.S. Energy Efficiency Standards for Residential Appliances: Update, Lawrence Berkeley National Laboratory, Report No. LBNL-56417, 2005 (forthcoming). 
Meyers, S., McMahon, J.E., McNeil, M., Liu, X. (2003). Impacts of US Federal Energy Efficiency Standards For Residential Appliances, Energy, Volume 28, Issue 8, pp. 755-767.

S Taib et all: 'Promoting Energy Awareness and Efficiency: USM Strategy', The 8th Int Conference on Quality in Research (QIR) 2005 Proc., EEE1-003.

CLASP, (2002). Web site of the collaborative labeling and appliance standards program. ohttp://www.CLASPonline.org

Duffy, J., (1996). Energy Labeling, Standards and Building Codes: A Global Survey and Assessment for Developing Countries. International Institute for Energy Conservation. Washington, DC.

J. Seabright, S.G Smith, H.L.Vierbicher, Market conditions affecting energy efficiency investments, Energy Conversion Engineering Conference, 1996. IECEC 96. Proceedings of the 31st Intersociety,Volume 3, 11-16 Aug. 1996 Page(s): 1546 - 1551 vol.3

P.H Salmon-Cox, Energy efficiency initiatives in emerging markets and developing countries;Energy Conversion Engineering Conference, 1996. IECEC 96. Proceedings of the 31st Intersociety,Volume 3, 11-16 Aug. 1996 Page(s):1542 - 1545 vol.3.

P. Bertoldim European code of conduct to improve energy efficiency of power supply: the first policy action around the worldwide addressing external power supplies, Applied Power Electronics Conference and Exposition, 2004 . APEC '04. Nineteenth Annual IEEE, Volume 1, 2004 Page(s):329 - 331 Vol.1

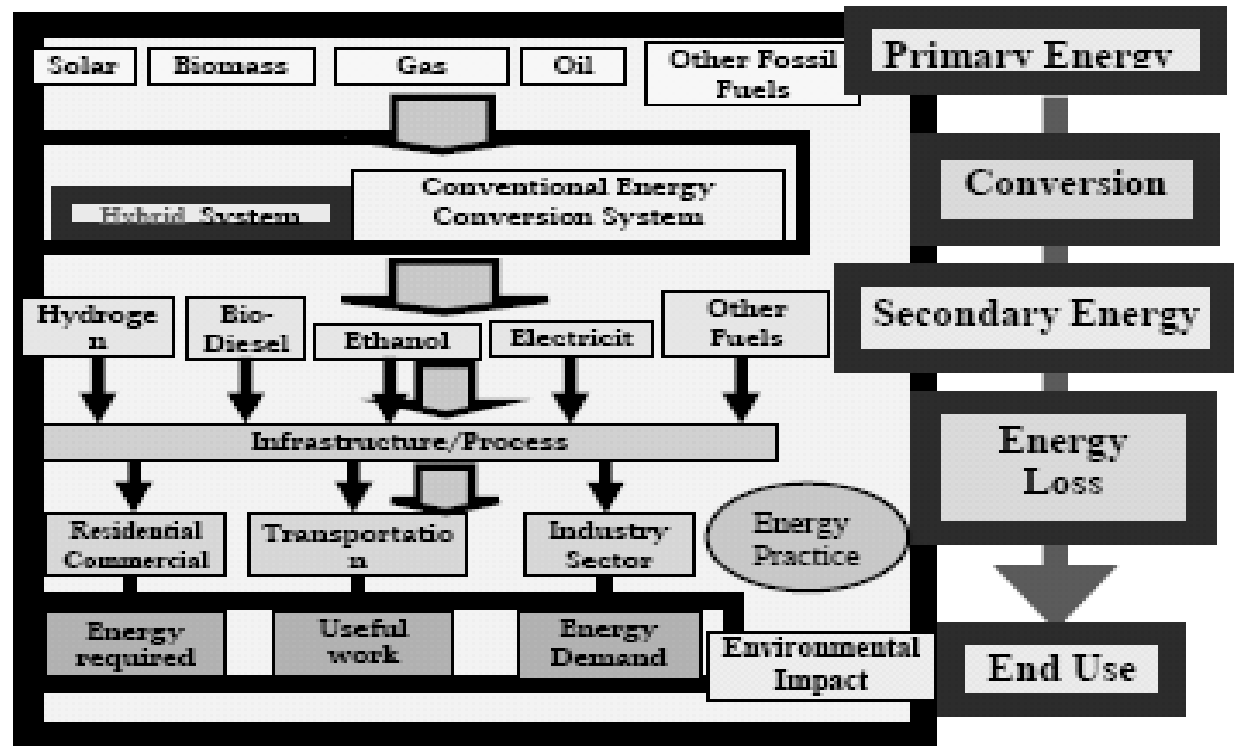

Figure 1. Energy Efficiency flow (Soib et, al .2005)

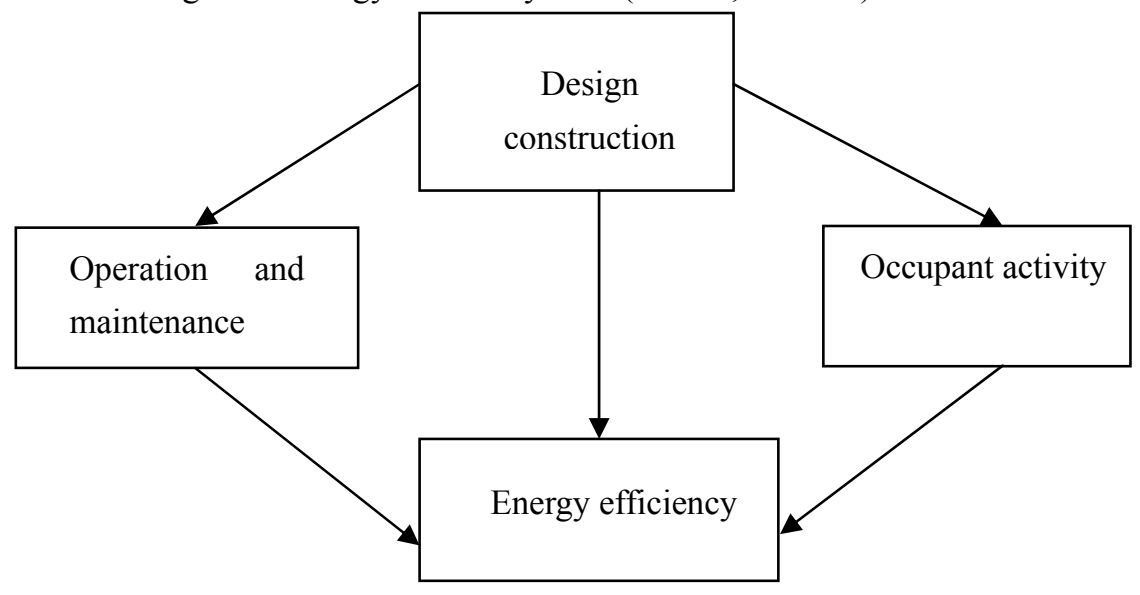

Figure 2. factors affecting energy efficiency 